\title{
Paeonol enhances the sensitivity of human ovarian cancer cells to radiotherapy-induced apoptosis due to downregulation of the phosphatidylinositol-3-kinase/Akt/phosphatase and tensin homolog pathway and inhibition of vascular endothelial growth factor
}

\author{
HAI-MEI ZHOU ${ }^{1}$, QIN-XIANG SUN ${ }^{2}$ and YAN CHENG ${ }^{3}$ \\ Departments of ${ }^{1}$ Obstetrics and Gynecology, and ${ }^{2}$ Internal Medicine, The Affiliated Hospital of Shandong \\ Medical College, Linyi, Shandong 276401; ${ }^{3}$ Department of Obstetrics and Gynecology, Obstetrics \\ and Gynecology Hospital Affiliated To Fudan University, Shanghai 200090, P.R. China
}

Received November 17, 2015; Accepted November 18, 2016

DOI: $10.3892 / \mathrm{etm} .2017 .4877$

\begin{abstract}
Radiotherapy is a vital and effective method to treat solid tumors. However, in many tumor types, development of resistance of cancer cells and cytotoxicity in normal tissues presents a major therapeutic problem. It is therefore crucial to identify and develop novel sensitizing agents that may improve the response to radiation therapy without causing any adverse effects. The present study aimed to investigate whether paeonol, a bioactive flavonoid, was able to confer sensitivity to radiation in human ovarian cancer cells. The human ovarian cancer cell lines SKOV-3 and OVCAR-3 were exposed to varying doses of radiation $(2,4$ or $6 \mathrm{~Gy})$ in the presence or absence of paeonol $(25,50$ or $100 \mu \mathrm{M})$. Radiosensitivity was assessed by measuring cell viability using a CCK-8 assay and Annexin V/PI staining. Expression of vascular endothelial growth factor (VEGF), hypoxia inducible factor-1 $\alpha$ (HIF-1 $\alpha)$, proteins of the phosphatidylinositol-3-kinase (PI3K)/Akt pathway and apoptotic pathway proteins [caspase-3, Bcl-2-associated death promoter, B-cell lymphoma (Bcl)-2, Bcl-2-associated $\mathrm{X}$ and $\mathrm{Bcl}-$ extra large (Bcl-xL)] were also assessed. Paeonol treatment enhanced apoptosis of SKOV-3 and OVCAR-3 cells that were exposed to radiation. The expression of $\mathrm{Bcl}-2$ and Bcl-xL were markedly upregulated in these cells. Treatment with paeonol concentrations of 50 and $100 \mu \mathrm{M}$ caused a significant downregulation of VEGF, HIF-1 $\alpha$ and PI3K/Akt pathway proteins. Paeonol effectively enhanced the sensitivity
\end{abstract}

Correspondence to: Dr Qin-Xiang Sun, Department of Internal Medicine, The Affiliated Hospital of Shandong Medical College, 80 Jintan Road, Linyi, Shandong 276401, P.R. China

E-mail: sunqinxiang848@126.com

Key words: apoptosis, ovarian cancer, paeonol, phosphatidylinositol-3-kinase/Akt pathway, radiotherapy, vascular endothelial growth factor of ovarian cancer cells to radiation by significantly altering regulation of the proteins of the PI3K/Akt pathway, in addition to downregulating VEGF and HIF-1 $\alpha$.

\section{Introduction}

Ovarian cancer is the most prevalent cancer amongst women, and is the third most frequent gynecological cancer, representing the most common cause of gynecological cancer-associated mortalities (1). Approximately about $70 \%$ of ovarian cancers are diagnosed at advanced stages and, even following surgery and chemotherapy, have high rates of recurrence (42-48\%) due to presence of residual disease at microscopic levels $(2,3)$. Radiation therapy may be employed to eliminate this residual disease that is subsequently responsible for recurrence (4). Several reports indicate an increased survival rate following radiation therapy when used in combination with surgery or with surgery and chemotherapy $(5,6)$. Radiotherapy has been demonstrated to induce a cytotoxic response in chemotherapy-resistant ovarian cancers, which increases the possibility of improved tumor control (7). However, cytotoxicity is considered to be a key limiting factor of radiotherapy use; therefore, agents that sensitize ovarian cancer cells to radiation therapy may be of significant clinical value in treatment of chemotherapy-resistant cancers, and in reducing the recurrence of cancer.

Tumor hypoxia is a common feature of malignant tumors, and contributes to resistance to radiotherapy (8). Hypoxia inducible factor-1 (HIF-1) is one of the key regulators of cell response to hypoxic conditions. HIF-1 $\alpha$, the oxygen-sensitive subunit of HIF-1, regulates the expression of numerous downstream target genes, such as vascular endothelial growth factor (VEGF), and is implicated in tumor resistance to radiotherapy and to chemotherapy $(9,10)$.

Furthermore, the phosphatidylinositol-3-kinase/ Akt/mammalian target of rapamycin (PI3K/Akt/mTOR) pathway regulates cell growth and proliferation. This pathway exerts crucial roles in apoptosis, tumor generation, tumor development and metastasis, and has been reported to be 
involved in resistance to radiotherapy $(11,12)$. In addition, phosphatase and tensin homolog (PTEN), a negative regulator of the PI3K/Akt/mTOR pathway, is a highly effective tumor suppressor (13). PTEN has also been reported to be frequently mutated in multiple human cancers $(14,15)$. Owing to the crucial roles in tumor pathogenesis, the PI3K/Akt/mTOR pathway is a critical target in cancer therapy. Therefore, identification of inhibitors of the pathway could potentially prevent tumor development and also may represent sensitizing agents to radiotherapy in cancer treatment.

Accumulating experimental data have demonstrated the potential of natural products as antitumor drugs (16). Paeonol (4-methoxy-2-hydroxyacetophenone), an active compound from the root bark of Paeonia suffruticosa, is used in traditional Chinese medicines $(17,18)$. Paeonol possesses various pharmacological properties, including antioxidant, anti-inflammatory and immunomodulatory effects (19-21). Lee et al (22) previously reported that paeonol inhibited cell migration and angiogenesis by downregulating PI3K/Akt signaling. Paeonol was also reported to sensitize lung adenocarcinoma cells to radiotherapy (23). Considering these diverse biological effects, the current study investigated whether paeonol inhibits tumor development in ovarian cancer cells, and whether it sensitizes these cells to radiation.

\section{Materials and methods}

Cell lines, equipment and reagents. The human ovarian carcinoma cell lines SKOV-3 and OVCAR-3 were obtained from ATCC and were cultured according to the instructions provided by ATCC. Cells were incubated with various doses of paeonol $(0,25,50$ or $100 \mu \mathrm{M})$ for $12 \mathrm{~h}$ and subsequently exposed to X-ray radiation for $24 \mathrm{~h}$, at doses of $0,2,4$ or $6 \mathrm{~Gy}$. Irradiation was performed at a dose rate of $0.40 \mathrm{~Gy} / \mathrm{min}$ using a 180-KVp X-ray generator [IXS2050; VJ Technologies China (Suzhou) Co., Ltd., Suzhou, China]. Paeonol was procured from Sigma-Aldrich (Merck KGaA, Darmstadt, Germany). Antibodies against VEGF (cat. no. 2463), HIF-1 $\alpha$ (cat. no. 79233), $\beta$-actin (cat. no. 3700), caspase-3 (cat. no. 9662; all Cell Signaling Technology Inc., Danvers, MA, USA), B-cell lymphoma (Bcl)-2 (cat. no. sc-509), Bcl-2-associated death promoter (Bad; cat. no. sc-943), Bcl-2-associated X (Bax; cat. no. sc-4239), Bcl-extra-large (xL; cat. no. sc-136132), Akt (cat. no. sc-24500), p-Akt (cat. no. sc-135650), glycogen synthase kinase (GSK)-3 $\beta$ (cat. no. sc-221692), p-GSK-3 $\beta$ (cat. no. sc-81494), mammalian target of rapamycin complex 1 (mTORc1; cat. no. sc-293089) and phosphatase and tensin homolog (PTEN; cat. no. sc-400103; all Santa Cruz Biotechnology, Inc., Dallas, TX, USA) were used for western blotting. All antibodies were used at 1:1,000.

All other reagents used in the study were of analytical grade and were procured from Sigma-Aldrich unless otherwise specified.

Cell viability assay. The sensitivity of SKOV3 and OVCAR-3 to radiation and/or paeonol was assayed using a Cell Counting kit-8 (CCK-8; Dojindo Laboratories, Kumamoto, Japan). Cells were incubated with paeonol $(25,50$ or $100 \mu \mathrm{M})$ for $12 \mathrm{~h}$ and then exposed to radiation. The control cells were exposed to equal volume of DMSO instead of paeonol. After radiation exposure for $24 \mathrm{~h}$, the cells were seeded in a 96-well plate at a density of $1 \times 10^{4}$ cells/well, and incubated for $48 \mathrm{~h}$ in an atmosphere containing $5 \% \mathrm{CO}_{2}$ at $37^{\circ} \mathrm{C}$. CCK-8 solution $(10 \mu \mathrm{l})$ was added to each well, and the plate was incubated for $2 \mathrm{~h}$ at room temperature. The absorbance at $450 \mathrm{~nm}$ was measured using a microplate reader (Synergy HT; Bio-Tek Instruments, Inc., Winooski, VT, USA).

Flow cytometry analysis for cell viability. Following irradiation for $24 \mathrm{~h}$, the cells were collected, resuspended in fresh medium and analyzed for viability using an Annexin V-fluorescein isothiocyanate apoptosis detection kit (BD Biosciences, San Jose, CA, USA), according to the manufacturer's instructions. The apoptotic cells were detected by flow cytometry (FACSCalibur with CellQuest software version 5.1; BD Biosciences).

Colony formation assay. A colony formation assay was performed as previously described (24). Following irradiation, cells $\left(1 \times 10^{3}\right.$ cells/plate) were seeded into 60-mm Petri dishes with standard culture medium (RPMI 1640; Sigma-Aldrich; Merck $\mathrm{KGaA}$ ) and incubated at $37^{\circ} \mathrm{C}$ in an atmosphere containing $5 \% \mathrm{CO}_{2}$. After 14 days of incubation, the cells were fixed with $4 \%$ formaldehyde and stained with crystal violet. Colonies containing $>50$ cells were counted and the surviving fraction was calculated by normalization to their respective non-irradiated control. The surviving fraction (SF) for a given dose of paeonol was calculated as follows: $\mathrm{SF}=$ number of colonies following irradiation/the number of cells inoculated $\mathrm{x}$ cell planting rate (i.e., the number of cells in the appropriate 0 Gy group). The multitarget click model in GraphPad Prism 5.0 (GraphPad Software Inc., La Jolla, CA, USA) was used to determine the cell survival curves.

Reverse transcription (RT)-polymerase chain reaction (PCR). Following exposure to paeonol and irradiation, cells were subjected to RT-PCR analysis to assess the expression of VEGF. The cells $\left(1 \times 10^{6}\right.$ cells) were lysed and total RNA was extracted using TRIzol reagent (Invitrogen; Thermo Fisher Scientific, Inc., Waltham, MA, USA) according to the manufacturer's protocol, followed by cDNA synthesis $(1 \mu \mathrm{g}$ RNA was used for cDNA synthesis) as described previously (25). VEGF-A mRNA levels were determined by PCR using a One-Step SYBR PrimeScript RT-PCR kit (Takara, Inc., Otsu, Japan) using a Thermal Cycler Dice Real Time System II (Takara Bio, Shiga, Japan) according to the manufacturer's protocol. The thermocyclying conditions were as follows: Initial denaturation at $95^{\circ} \mathrm{C}$ for $8 \mathrm{sec}$ followed by 45 cycles of denaturation at $95^{\circ} \mathrm{C}$ for $3-6 \mathrm{sec}$ and annealing and extension at $60^{\circ} \mathrm{C}$ for $35-38 \mathrm{sec}$. The primers used were as follows: VEGF-A: Forward, 5'-CCAGCAGAAAGAGGAAAG AGGTAG-3'; reverse, 5'-CCCCAAAAGCAGGTCACTCAC-3'; GAPDH: Forward, 5'-GAAGGTGAAGGTCGGAGTC-3'; and reverse, 5'-GAAGATGGTGATGGGATTTC-3'. VEGF expression levels were normalized to those of GAPDH expression. The intensity of the PCR products was determined using Image Lab version 4.1 (Bio-Rad Laboratories, Inc., Hercules, CA, USA).

Western blotting. Cells were harvested after $24 \mathrm{~h}$ following irradiation and were lysed as described previously (26). Protein concentration was determined by Bradford assay using a protein assay kit (Bio-Rad Laboratories, Inc.). An equal concentration 


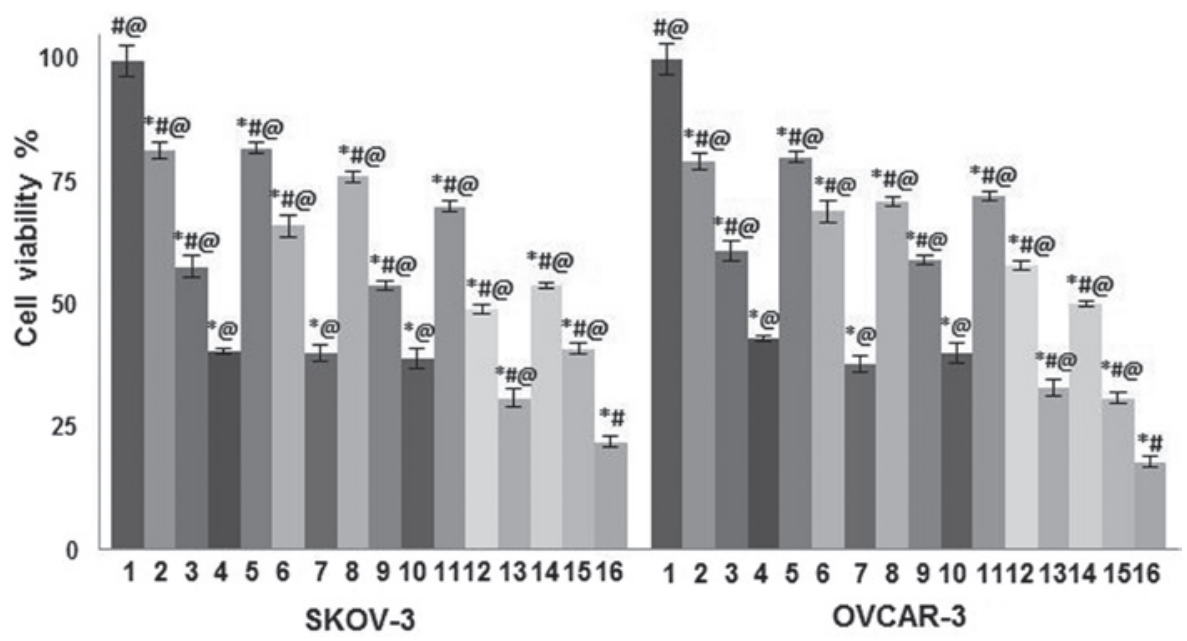

Figure 1. Effect of paeonol on cell viability, determined by a cell counting kit-8. Values are presented as mean \pm standard deviation; $\mathrm{n}=6$ experiments. ${ }^{*} \mathrm{P}<0.05$ vs. control, " $\mathrm{P}<0.05$ vs group $7,{ }^{\circledR} \mathrm{P}<0.05$ vs. group 16.1 , Control; $2,25 \mu \mathrm{M}$ paeonol; $3,50 \mu \mathrm{M}$ paeonol; $4,100 \mu \mathrm{M}$ paeonol; 5, $2 \mathrm{~Gy} ; 6,4 \mathrm{~Gy} ; 7,6 \mathrm{~Gy} ; 8,25 \mu \mathrm{M}$ paeonol $+2 \mathrm{~Gy} ; 9,50 \mu \mathrm{M}$ paeonol $+2 \mathrm{~Gy} ; 10,100 \mu \mathrm{M}$ paeonol $+2 \mathrm{~Gy} ; 11,25 \mu \mathrm{M}$ paeonol $+4 \mathrm{~Gy} ; 12,50 \mu \mathrm{M}$ paeonol $+4 \mathrm{~Gy} ; 13,100 \mu \mathrm{M}$ paeonol $+4 \mathrm{~Gy} ; 14$, $25 \mu \mathrm{M}$ paeonol $+6 \mathrm{~Gy} ; 15,50 \mu \mathrm{M}$ paeonol $+6 \mathrm{~Gy} ; 16,100 \mu \mathrm{M}$ paeonol $+6 \mathrm{~Gy}$.

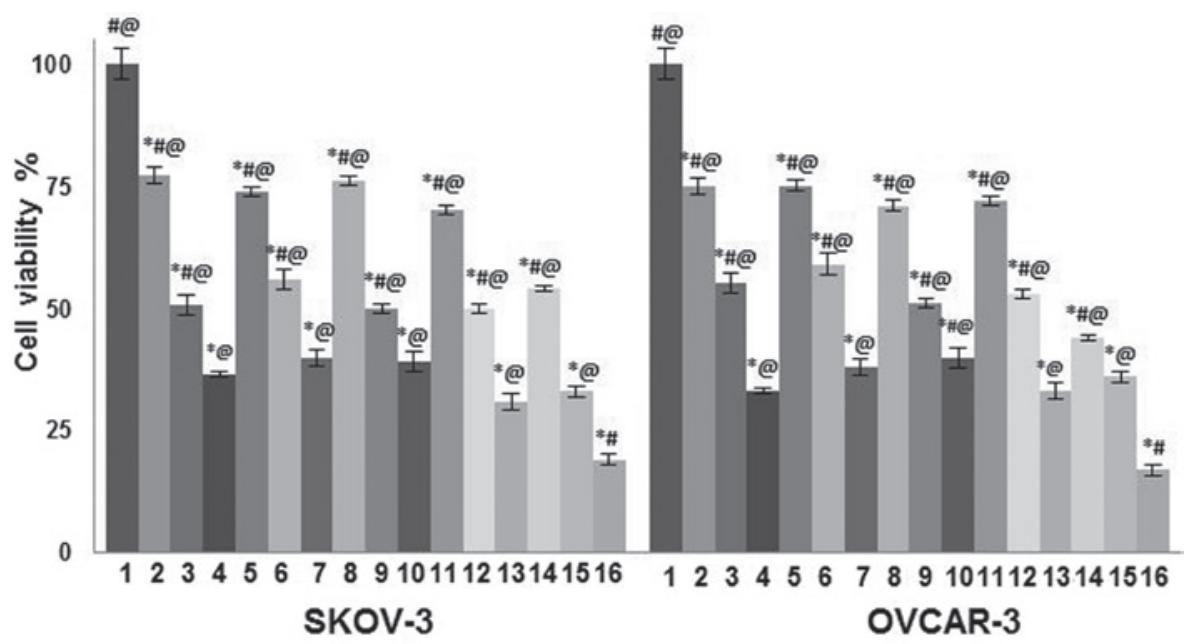

Figure 2. Effect of paeonol on apoptosis in ovarian cancer cells, based on flow cytometric analysis. Values are presented as mean \pm standard deviation; $\mathrm{n}=6$ experiments. ${ }^{*} \mathrm{P}<0.05$ vs. control, ${ }^{, \mathrm{P}}<0.05$ vs. group $7,{ }^{\circledR} \mathrm{P}<0.05$ vs. group 16.1 , Control; $2,25 \mu \mathrm{M}$ paeonol; $3,50 \mu \mathrm{M}$ paeonol; $4,100 \mu \mathrm{M}$ paeonol; $5,2 \mathrm{~Gy} ; 6$, 4 Gy; 7, 6 Gy; 8, $25 \mu \mathrm{M}$ paeonol $+2 \mathrm{~Gy} ; 9,50 \mu \mathrm{M}$ paeonol $+2 \mathrm{~Gy} ; 10,100 \mu \mathrm{M}$ paeonol $+2 \mathrm{~Gy} ; 11,25 \mu \mathrm{M}$ paeonol $+4 \mathrm{~Gy} ; 12,50 \mu \mathrm{M}$ paeonol $+4 \mathrm{~Gy} ; 13$, $100 \mu \mathrm{M}$ paeonol $+4 \mathrm{~Gy} ; 14,25 \mu \mathrm{M}$ paeonol $+6 \mathrm{~Gy} ; 15,50 \mu \mathrm{M}$ paeonol $+6 \mathrm{~Gy} ; 16-100 \mu \mathrm{M}$ paeonol $+6 \mathrm{~Gy}$.

of total protein $(60 \mu \mathrm{g})$ from cells of each treatment group was subjected to electrophoresis by SDS-PAGE, and the separated proteins were blotted and transferred onto nitrocellulose membranes. The membranes were blocked with 5\% skim milk and incubated with primary antibodies overnight at $4^{\circ} \mathrm{C}$. This was followed by incubation with horseradish peroxidase-conjugated secondary antibodies at room temperature for $1 \mathrm{~h}$. The immunoreactive bands were detected by enhanced chemiluminescence (GE Healthcare Life Sciences, Little Chalfont, UK). The densities of the positive bands were further analysed by ImageQuant TL software (version 7.0; GE Healthcare Life Sciences). The analyzed protein band densities were normalized to those of $\beta$-actin using anti- $\beta$-actin antibodies.

Statistical analysis. The values obtained are presented as mean \pm standard deviation, from six independent experiments. The data were analyzed for statistical significance by one-way analysis of variance and post-hoc analysis by Duncan's
Multiple Range Test. $\mathrm{P}<0.05$ was considered to indicate a statistically significant difference.

\section{Results}

Paeonol reduces the viability of ovarian cancer cells. The cytotoxic effects of paeonol on non-irradiated and irradiated carcinoma cells were determined using a CCK-8 assay. Paeonol significantly inhibited the proliferation of all cell lines in a dose-dependent manner, irrespective of exposure to radiation $(\mathrm{P}<0.05$; Fig. 1). Paeonol also improved the sensitivity of SKOV-3 and OVCAR-3 cells to radiation, in a dose-dependent manner; when compared with the cells irradiated but not treated with paeonol, viability was significantly reduced following combined exposure $(\mathrm{P}<0.05)$ (Fig. 1). Flow cytometric analysis for assessment of apoptotic cell counts by Annexin V/FITC staining revealed comparable results (Fig. 2). In both assays, the highest dose of paeonol (100 $\mu \mathrm{M})$ 


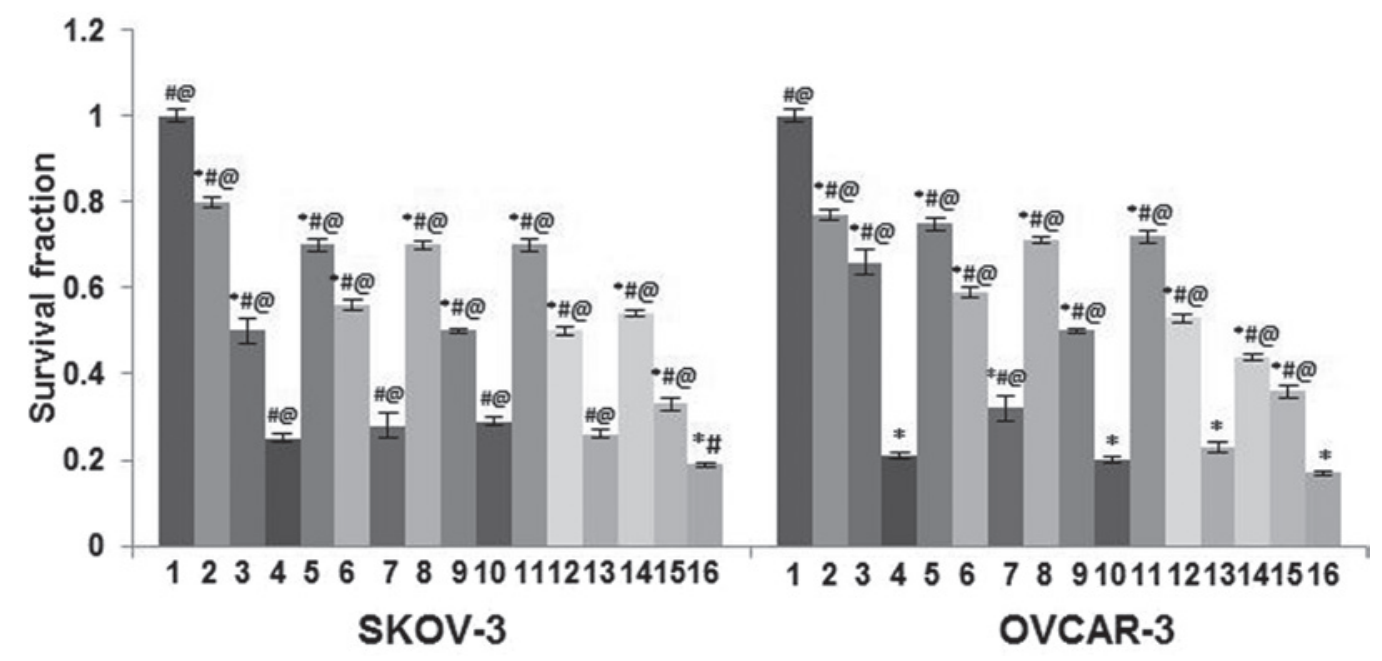

Figure 3. Effect of paeonol on survival fraction in ovarian cancer cells, based on a clonogenic assay. Values are presented as mean \pm standard deviation; $\mathrm{n}=6$ experiments. " $\mathrm{P}<0.05$ vs. control, ${ }^{\#} \mathrm{P}<0.05$ vs. group $7,{ }^{\circledR} \mathrm{P}<0.05$ vs. group 16 . 1 , Control; $2,25 \mu \mathrm{M}$ paeonol; $3,50 \mu \mathrm{M}$ paeonol; $4,100 \mu \mathrm{M}$ paeonol; $5,2 \mathrm{~Gy} ; 6,4$ Gy; 7, $6 \mathrm{~Gy} ; 8,25 \mu \mathrm{M}$ paeonol $+2 \mathrm{~Gy} ; 9,50 \mu \mathrm{M}$ paeonol $+2 \mathrm{~Gy} ; 10,100 \mu \mathrm{M}$ paeonol $+2 \mathrm{~Gy} ; 11,25 \mu \mathrm{M}$ paeonol $+4 \mathrm{~Gy} ; 12,50 \mu \mathrm{M} \mathrm{paeonol}+4 \mathrm{~Gy} ; 13,100 \mu \mathrm{M}$ paeonol $+4 \mathrm{~Gy} ; 14,25 \mu \mathrm{M}$ paeonol $+6 \mathrm{~Gy} ; 15,50 \mu \mathrm{M}$ paeonol $+6 \mathrm{~Gy} ; 16-100 \mu \mathrm{M}$ paeonol $+6 \mathrm{~Gy}$.

exhibited the maximum cytotoxic effects. These results indicate that paeonol effectively inhibited viability of cancer cells and induced apoptosis, in addition to enhancing sensitivity of the two cell lines to radiation.

Paeonol sensitizes ovarian cancer cells to radiation. Treatment with paeonol $(25,50$ or $100 \mu \mathrm{M})$ significantly enhanced the intrinsic sensitivity of both SKOV-3 and OVCAR-3 cells to radiation, as assessed by clonogenic survival assays as compared with cells exposed to radiation alone $(\mathrm{P}<0.05$; Fig. 3$)$. The surviving fraction of the cells was significantly reduced with an increase in radiation dose from 4 to $6 \mathrm{~Gy}(\mathrm{P}<0.05)$. The cells exposed to paeonol and radiation presented a much lower $\mathrm{SF}$ than the cells exposed to either radiation or paeonol. The cells exposed to $6 \mathrm{~Gy}$ radiation and $100 \mu \mathrm{M}$ paeonol were observed to have a significantly lower SF compared with cells exposed to 4 and 2 Gy radiation, irrespective of paeonol concentration. Nevertheless, paeonol at all doses was demonstrated to be more effective in sensitizing SKOV-3 cells to radiation than OVCAR-3 cells.

Paeonol modulates the expression of apoptotic pathway proteins. To assess the molecular events associated with reduced cell viability of the SKOV-3 and OVCAR-3 cells following exposure to paeonol, the expression of caspase-3 and pro-apoptotic (Bad and Bax) and anti-apoptotic (Bcl-2 and $\mathrm{Bcl}-\mathrm{xL}$ ) proteins were determined. Paeonol treatment was revealed to enhance the expression of caspase- 3 in a dose-dependent manner (Fig. 4). Furthermore, corresponding with the apoptotic cell counts observed through Annexin V/PI staining, the expression of Bad and Bax proteins was significantly upregulated in cells exposed to paeonol and/or radiation. However, combined exposure revealed strikingly increased levels of apoptotic proteins, with markedly downregulated $\mathrm{Bcl}-2$ and $\mathrm{Bcl}-\mathrm{xL}$ proteins. This expression analysis suggests the possible involvement of apoptotic proteins in paeonol-mediated enhanced sensitivity to radiation in the SKOV-3 and OVCAR3 cells.
Paeonol downregulates HIF-1 $\alpha$ and VEGF expression. HIF-1, the expression of which is induced by hypoxic tumor conditions, has been implicated in radiation-resistant tumor cells (27), and HIF-1 regulates the expression of VEGF (28). PCR and Western blot analyses to determine VEGF and HIF-1 $\alpha$ expression revealed that expression of these mRNA sequences and corresponding proteins may be modulated by paeonol (Fig. 5). Notably, downregulated expression was observed in irradiated cells with no exposure to paeonol. However, paeonol at doses of 50 and $100 \mu \mathrm{M}$ caused significantly greater reductions in expression levels of both HIF-1 $\alpha$ and VEGF, and the expression level of VEGF mRNA corresponded to this, suggesting that paeonol affected the expression at the gene level. These expression analyses revealed the involvement of HIF-1 and VEGF in the paeonol-induced response.

Effects of paeonol on the proteins of PI3K/Akt signaling cascade. The PI3K/Akt signaling pathway serves an important role in the regulation of cell survival, proliferation and apoptosis (29). Previous studies have indicated that inhibition of the pathway effectively enhances the sensitivity of lung cancer cells and cervical cancer cells to radiation $(30,31)$. The present study noted markedly higher expression of Akt, p-Akt and mTORc1 in ovarian cancer cells that were not exposed to paeonol or radiation (Fig. 6). Irradiated cells in all paeonol treatment groups exhibited significantly downregulated expression of Akt and p-Akt, GSK-3 $\beta, \mathrm{p}-\mathrm{GSK}-3 \beta$ and mTORc1, and markedly increased PTEN expression. Furthermore, this downregulation was more pronounced with $100 \mu \mathrm{M}$ paeonol concentration at all radiation dose levels. These observations suggest that the inhibition of the PI3K/Akt pathway by paeonol may enhance the sensitivity of ovarian cancer cells to radiation.

\section{Discussion}

Ovarian cancer is one of the prevalent cancers in women (1) and radiotherapy is often employed in treatment following surgery (4). However, development of resistance to radiation 


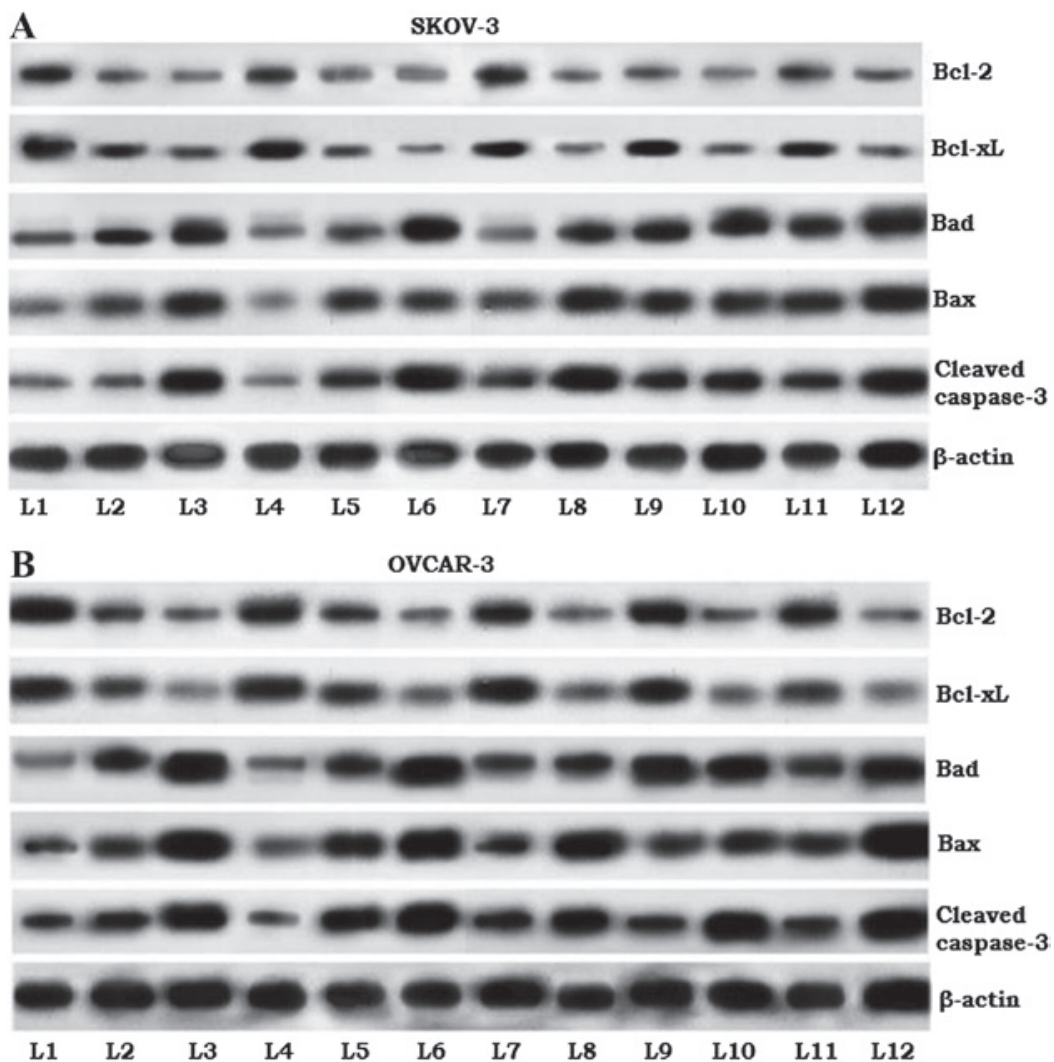

Figure 4. Effects of paeonol on the expression of apoptosis pathway proteins in (A) SKOV3 and (B) OVCAR-3 cells. L1, control; L2, $50 \mu \mathrm{M}$ paeonol only; L3, $100 \mu \mathrm{M}$ paeonol only; L4, 2 Gy radiation only; L5, 4 Gy radiation only; L6, 6 Gy radiation only; L7, $50 \mu \mathrm{M}$ paeonol +2 Gy radiation; L8, $100 \mu \mathrm{M}$ paeonol + 2 Gy radiation; $\mathrm{L} 9,50 \mu \mathrm{M}$ paeonol $+4 \mathrm{~Gy}$ radiation; L10, $100 \mu \mathrm{M}$ paeonol +4 Gy radiation; L11, $50 \mu \mathrm{M}$ paeonol +6 Gy radiation; L12, $100 \mu \mathrm{M}$ paeonol +6 Gy radiation. Bcl-2, B-cell lymphoma-2; Bcl-xL, Bcl-extra large; Bad, Bcl-2-associated death promoter; Bax, Bcl-2-associated X.

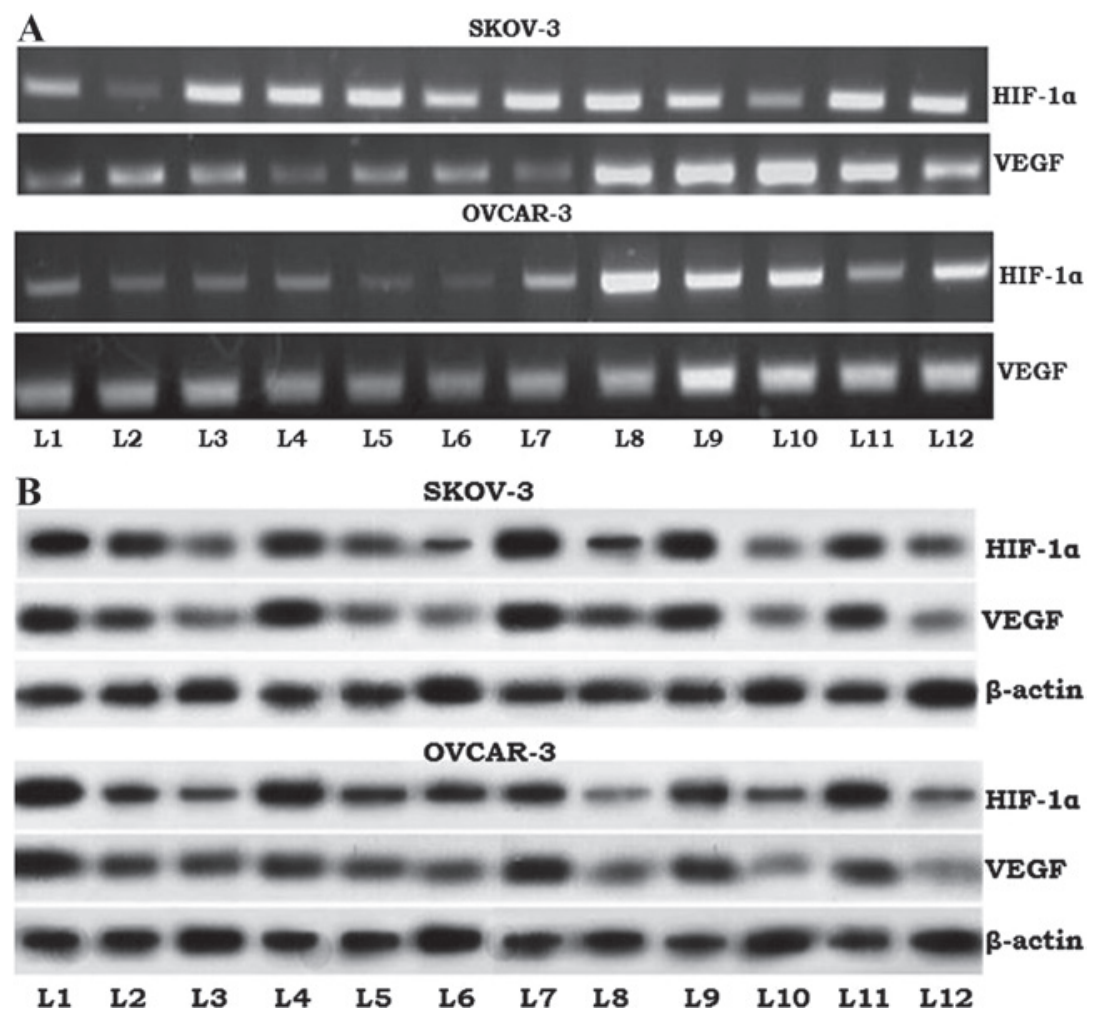

Figure 5. Effects of paeonol on the apoptosis pathway components HIF-1 $\alpha$ and VEGF in the ovarian cancer cell lines SKOV-3 and OVCAR-3, as observed by (A) reverse transcription-polymerase chain reaction and (B) western blotting. L1, control; L2, $50 \mu \mathrm{M}$ paeonol only; L3, $100 \mu \mathrm{M}$ paeonol only; L4, 2 Gy radiation only; L5, 4 Gy radiation only; L6, 6 Gy radiation only; L7, $50 \mu \mathrm{M}$ paeonol +2 Gy radiation; L8, $100 \mu \mathrm{M}$ paeonol +2 Gy radiation; L9, 50 $\mu \mathrm{M}$ paeonol +4 Gy radiation; L10, $100 \mu \mathrm{M}$ paeonol +4 Gy radiation; L11, $50 \mu \mathrm{M}$ paeonol + 6 Gy radiation; L12, $100 \mu \mathrm{M}$ paeonol + 6 Gy radiation. HIF, hypoxia inducible factor; VEGF, vascular endothelial growth factor. 


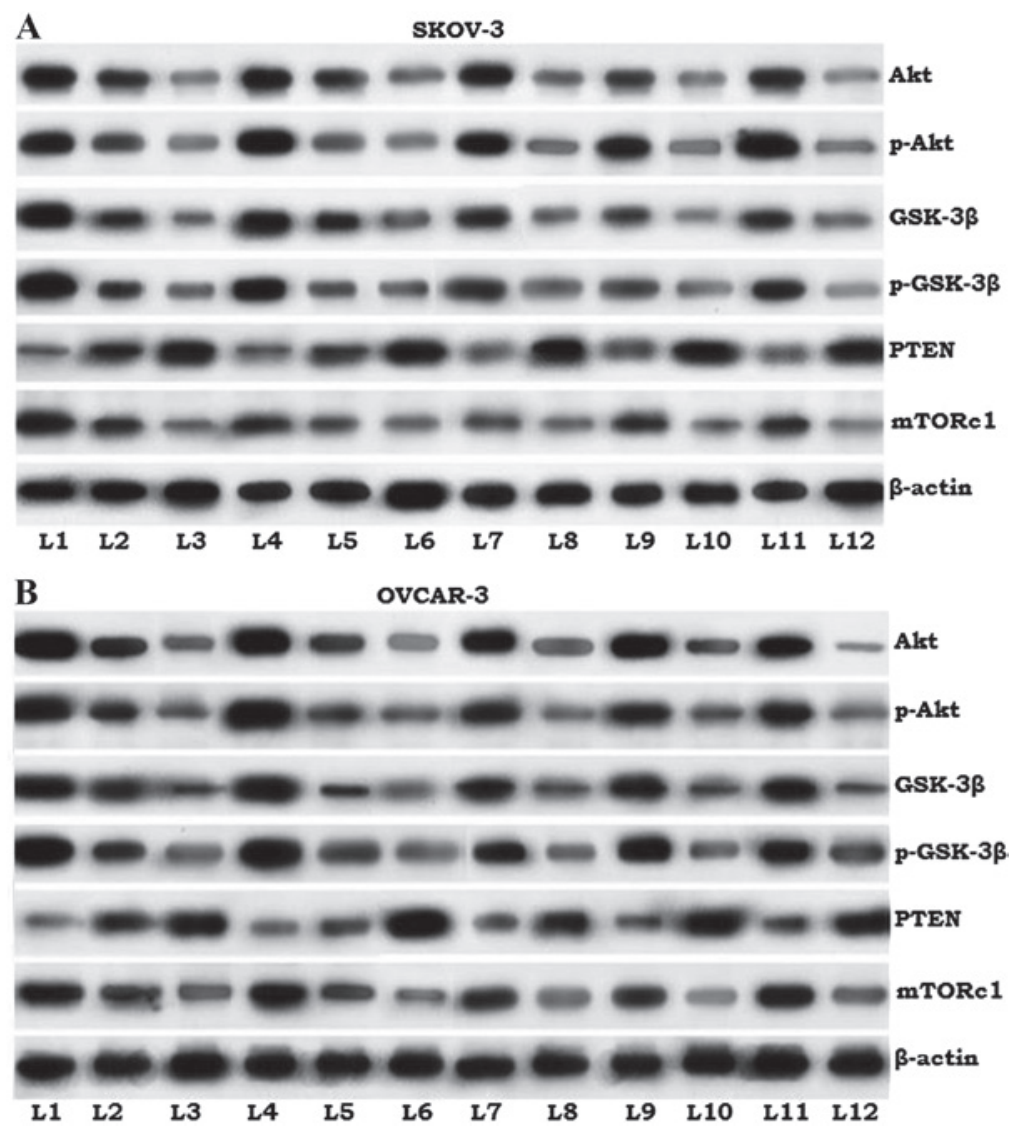

Figure 6. Effects of paeonol on proteins of the PI3K/Akt/mTOR pathway in (A) SKOV3 and (B) OVCAR-3 cells. L1, control; L2, $50 \mu \mathrm{M}$ paeonol only; L3, $100 \mu \mathrm{M}$ paeonol only; L4, 2 Gy radiation only; L5, 4 Gy radiation only; L6, 6 Gy radiation only; L7, $50 \mu \mathrm{M}$ paeonol +2 Gy radiation; L8, $100 \mu \mathrm{M}$ paeonol + 2 Gy radiation; L9, $50 \mu \mathrm{M}$ paeonol +4 Gy radiation; $\mathrm{L} 10,100 \mu \mathrm{M}$ paeonol +4 Gy radiation; L11, $50 \mu \mathrm{M}$ paeonol +6 Gy radiation; L12, $100 \mu \mathrm{M}$ paeonol +6 Gy radiation. GSK, glycogen synthase kinase; PTEN, phosphatase and tensin homolog; mTORc1, mammalian target of rapamycin complex 1.

is currently a major obstacle. Understanding the mechanisms and the signaling pathways associated with regulation of resistance to radiation is crucial in development of approaches to overcome this. Previous research has focused on identifying tumor-specific sensitizing agents to enhance radiotherapy, and multiple studies have demonstrated the effect of many natural compounds, including curcumin and berberine, in improving sensitivity of cancer cells to radiation (31-33). A previous study has also reported the antitumor effects of paeonol on human lung adenocarcinoma cells (34).

In the present study, CCK-8 assays revealed that paeonol markedly reduced the viability of SKOV-3 and OVCAR-3 cells that were subjected to radiation. The antitumor effects of paeonol have previously been demonstrated to be associated with induction of apoptosis, cell cycle arrest, activation of interleukin-2 and tumor necrosis factor- $\alpha$, and modulation of Bcl-2 and Bax expression in tumor cells have been reported (35-38).

A decrease in the survival fraction (clonogenic assay) and paeonol-enhanced apoptosis (AnnexinV/PI staining assay) were observed in the current study. Furthermore, paeonol was also revealed to modulate the expression of apoptotic proteins in support of these apoptotic counts. A significant increase in caspase-3, Bad and Bax levels, and downregulation of Bcl-2 and Bcl-xL were observed. Paeonol was also reported, in the present study, to enhance the expression of pro-apoptotic proteins in irradiated cells, suggesting an induction of apoptosis. These observations indicate that paeonol markedly increased the sensitivity of ovarian cancer cells to radiation.

Previous studies have suggested that hypoxia is one of the most influential factors in resistance of solid tumors to radiation (27,39-41). Hypoxia in tumors results from the imbalance between the increased oxygen consumption caused by extensive growth of tumor cells and poor oxygen delivery by disorganized tumor blood vessels (42). Drugs that target the hypoxia associated with resistance to radiation have had promising results (43). In the current study, paeonol caused marked downregulation of HIF- $1 \alpha$ and VEGF in a dose-dependent manner with all tested radiation doses. HIF-1 $\alpha$ is the oxygen-sensitive subunit of HIF and is induced by hypoxia, but the expression decreases under normoxic conditions (44). However, HIF-1 $\alpha$ is upregulated in hypoxic tumour tissues, which may contribute to resistance to radiation (45). Previous studies have demonstrated a positive correlation between the expression levels of HIF-1 and resistance of many solid tumors to radiation $(31,46)$. Hypoxia-induced HIF- $1 \alpha$ expression activates VEGF, stimulates angiogenesis and promotes the resistance of cancer cells to chemotherapy and radiotherapy $(47,48)$. Given the critical impact of HIF-1 $\alpha$ induced by hypoxia and radiation, effective inhibition of HIF-1 $\alpha$ may aid sensitization of tumor cells to chemotherapy and radiotherapy. Therefore, the marked downregulation of HIF-1 $\alpha$ and VEGF observed following paeonol treatment may have been 
responsible for the raised apoptotic cell counts observed in the irradiated ovarian cancer cell lines.

To better assess the molecular events associated with paeonol-induced sensitivity to radiation, the influence of paeonol on PI3K/Akt pathway proteins was examined, as several prior studies have reported associations between the PI3K pathway and resistance to radiation $(49,50)$. The PI3K/Akt/mTOR pathway is closely associated with pathways such as the androgen receptor pathway (51), the Ras/Raf/mitogen-activated protein kinase kinase/extracellular signal-regulated kinase pathway (52) eventually contributing to cancer cell proliferation, metastasis and resistance (52). Akt, a focal regulator of this pathway is considered to be a potential target in addressing sensitization to radiation. Upon activation, Akt phosphorylates many other downstream proteins such as mTOR, GSK3 and insulin receptor substrate-1 (53). Palomid 529, a novel and potent Akt inhibitor was also previously observed to increase sensitivity to radiation (54). In the current study, reduced phosphorylation of Akt and GSK-3 $\beta$, and suppressed expression of mTORc1 were observed, indicating inhibition of the PI3K/Akt/mTOR pathway. mTORC1 regulates cell growth through phosphorylation of S6 kinase (55) and induces increased expression of VEGF (56). Therefore, downregulation of VEGF may have been associated with suppression of mTORc1.

Furthermore, PTEN that acts at the molecular level to counteract the functions of PI3K was upregulated by paeonol, acting to inhibit the activated PI3K pathways. This suppression may be responsible for the enhanced apoptosis and sensitivity to radiation.

The observations of the present study suggest that paeonol induces apoptosis of irradiated ovarian cancer cells via modulation of the critical pathways involved in resistance to radiation, namely the HIF-1 $\alpha /$ VEGF pathway and PI3K/Akt/mTOR signalling cascades. Therefore, the present study indicates that paeonol may represent a potent sensitizing agent to radiation, which may be of further assistance in cancer therapy.

\section{References}

1. Jemal A, Siegel R, Ward E, Hao Y, Xu J, Murray T and Thun MJ: Cancer statistics, 2008. CA Cancer J Clin 58: 71-96, 2008.

2. Di Giorgio A, Naticchioni E, Biacchi D, Sibio S, Accarpio F, Rocco M, Tarquini S, Di Seri M, Ciardi A, Montruccoli D and Sammartino P: Cytoreductive surgery (peritonectomy procedures) combined with hyperthermic intraperitoneal chemotherapy (HIPEC) in the treatment of diffuse peritoneal carcinomatosis from ovarian cancer. Cancer 113: 315-325, 2008.

3. Tentes AA, Korakianitis OS, Kakolyris S, Kyziridis D, Veliovits D, Karagiozoglou C, Sgouridou E and Moustakas K: Cytoreductive surgery and periopeartive intraperitoneal chemotherapy in recurrent ovarian cancer. Tumori 96: 411-416, 2010.

4. Mosalaei A and Kazerooni T: Results of post-operative abdomino-pelvic radiotherapy in intermediate- and high-risk epithelial ovarian carcinoma. Eur J Cancer Care (Engl) 17: 371-376, 2008

5. Marsden DE, Friedlander M and Hacker NF: Current management of epithelial ovarian carcinoma: A review. Semin Surg Oncol 19: 11-19, 2000.

6. Firat S, Murray K and Erickson B: High-dose whole abdominal and pelvic irradiation for treatment of ovarian carcinoma: Long-term toxicity and outcomes. Int J Radiat Oncol Biol Phys 57: 201-207, 2003.

7. Gao Y, Liu Z, Chen X, Luo W, Zhang L and Wang J: Intraoperative radiotherapy electron boost in advanced and recurrent epithelial ovarian carcinoma: A retrospective study. BMC Cancer 11: 439, 2011.
8. Jiang XD, Qiao Y, Dai P, Wu J, Song DA, Li SQ and Fan YW: Preliminary clinical study of weekly recombinant human endostatin as a hypoxic tumour cell radiosensitiser combined with radiotherapy in the treatment of NSCLC. Clin Transl Oncol 14: 465-470, 2012.

9. Ikeda E: Cellular response to tissue hypoxia and its involvement in disease progression. Pathol Int 55: 603-610, 2005.

10. Chi KH, Wang YS and Kao SJ: Improving radioresponse through modification of the tumor immunological microenvironment. Cancer Biother Radiopharm 27: 6-11, 2012.

11. Chang L, Graham PH, Hao J, Ni J, Bucci J, Cozzi PJ, Kearsley JH and Li Y: Acquisition of epithelial-mesenchymal transition and cancer stem cell phenotypes is associated with activation of the $\mathrm{PI} 3 \mathrm{~K} / \mathrm{Akt} / \mathrm{mTOR}$ pathway in prostate cancer radioresistance. Cell Death Dis 4: e875, 2013.

12. Ni J, Cozzi P, Hao J, Beretov J, Chang L, Duan W, Shigdar S, Delprado W, Graham P, Bucci J, et al: Epithelial cell adhesion molecule (EpCAM) is associated with prostate cancer metastasis and chemo/radioresistance via the PI3K/Akt/mTOR signaling pathway. Int J Biochem Cell Biol 45: 2736-2748, 2013.

13. Chang L, Graham PH, Hao J, Bucci J, Cozzi PJ, Kearsley JH and $\mathrm{Li}$ Y: Emerging roles of radioresistance in prostate cancer metastasis and radiation therapy. Cancer Metastasis Rev 33: 469-496, 2014.

14. Sircar K, Yoshimoto M, Monzon FA, Koumakpayi IH, Katz RL, Khanna A, Alvarez K, Chen G, Darnel AD, Aprikian AG, et al: PTEN genomic deletion is associated with p-Akt and AR signalling in poorer outcome, hormone refractory prostate cancer. J Pathol 218: 505-513, 2009

15. de Muga S, Hernandez S, Agell L, Salido M, Juanpere N, Lorenzo M, Lorente JA, Serrano S and Lloreta J: Molecular alterations of EGFR and PTEN inprostate cancer: Association with high-grade and advanced-stage carcinomas. Mod Pathol 23: 703-712, 2010.

16. Qi F, Li A, Inagaki Y, Gao J, Li J, Kokudo N, Li XK and Tang W: Chinese herbal medicines as adjuvant treatment during chemo- or radiotherapy for cancer. Biosci Trends 4: 297-307, 2010.

17. Lau CH, Chan CM, Chan YW, Lau KM, Lau TW, Lam FC, Law WT, Che CT, Leung PC, Fung KP, et al: Pharmacological investigations of the anti-diabetic effect of Cortex Moutan and its active component paeonol. Phytomedicine 14: 778-784, 2007.

18. Nizamutdinova IT, Oh HM, Min YN, Park SH, Lee MJ, Kim JS, Yean MH, Kang SS, Kim YS, Chang KC and Kim HJ: Paeonol suppresses intercellular adhesion molecule-1 expression in tumor necrosis factor-alpha-stimulated human umbilical vein endothelial cells by blocking p38, ERK and nuclear factor-kappaB signaling pathways. Int Immunopharmacol 7: 343-350, 2007.

19. Kim SH, Kim SA, Park MK, Kim SH, Park YD, Na HJ, Kim HM, Shin MK and Ahn KS: Paeonol inhibits anaphylactic reaction by regulating histamine and TNF-alpha. Int Immunopharmacol 4: 279-287, 2004

20. Huang H, Chang EJ, Lee Y, Kim JS, Kang SS and Kim HH: A genome-wide microarray analysis reveals anti-inflammatory target genes of paeonol in macrophages. Inflamm Res 57: 189-198, 2008.

21. Zhong SZ, Ge QH, Qu R, Li Q and Ma SP: Paeonol attenuates neurotoxicity and ameliorates cognitive impairment induced by d-galactose in ICR mice. J Neurol Sci 277: 58-64, 2009.

22. Lee HJ, Kim SA, Lee HJ, Jeong SJ, Han I, Jung JH, Lee EO, Zhu S, Chen CY and Kim SH: Paeonol oxime inhibits bFGF-induced angiogenesis and reduces VEGF levels in fibrosarcoma cells. PLoS One 5: e12358, 2010.

23. Lei Y, Li HX, Jin WS, Peng WR, Zhang CJ, Bu LJ, Du YY, Ma T and Sun GP: The radiosensitizing effect of Paeonol on lung adenocarcinoma by augmentation of radiation-induced apoptosis and inhibition of the PI3K/Akt pathway. Int J Radiation Biol 89: 1079-1086, 2013.

24. Liang B, Kong D, Liu Y, Liang N, He M, Ma S and Liu X: Autophagy inhibition plays the synergetic killing roles with radiation in the multi-drug resistant SKVCR ovarian cancer cells. Radiat Oncol 7: 213, 2012.

25. Kashiyama T, Oda K, Ikeda Y, Shiose Y, Hirota Y, Inaba K, Makii C, Kurikawa R, Miyasaka A, Koso T, et al: Antitumor activity and induction of TP53-dependent apoptosis toward ovarian clear cell adenocarcinoma by the dual PI3K/mTOR inhibitor DS-7423. PLoS One 9: e87220, 2014. 
26. Oda K, Okada J, Timmerman L, Rodriguez-Viciana P, Stokoe D, Shoji K, Taketani Y, Kuramoto H, Knight ZA, Shokat KM and McCormick F: PIK3CA cooperates with other phosphatidylinositol 3'-kinase pathway mutations to effect oncogenic transformation. Cancer Res 68: 8127-8136, 2008.

27. Moeller BJ and Dewhirst MW: HIF-1 and tumour radiosensitivity. Br J Cancer 95: 1-5, 2006.

28. Yang Y, Sun M, Wang L and Jiao B: HIFs, angiogenesis, and cancer. J Cell Biochem 114: 967-974, 2013.

29. Opel D, Westhoff MA, Bender A, Braun V, Debatin KM and Fulda S: Phosphatidylinositol 3-kinase inhibition broadly sensitizes glioblastoma cells to death receptor- and drug-induced apoptosis. Cancer Res 68: 6271-6280, 2008.

30. Zhang T, Cui GB, Zhang J, Zhang F, Zhou YA, Jiang T and Li XF: Inhibition of PI3 kinases enhances the sensitivity of non-small cell lung cancer cells to ionizing radiation. Oncol Rep 24: 1683-1689, 2010.

31. Liu Q, Jiang H, Liu Z, Wang Y, Zhao M, Hao C, Feng S, Guo H, $\mathrm{Xu} \mathrm{B}$, Yang Q, et al: Berberine radiosensitizes human esophageal cancer cells by downregulating homologous recombination repair protein RAD51. PLoS One 6: e23427, 2011.

32. Peng PL, Kuo WH, Tseng HC and Chou FP: Synergistic tumor-killing effect of radiation and berberine combined treatment in lung cancer: The contribution of autophagic cell death Int J Radiat Oncol Biol Phys 70: 529-542, 2008.

33. Orr WS, Denbo JW, Saab KR, Ng CY, Wu J, Li K, Garner JM, Morton CL, Du Z, Pfeffer LM and Davidoff AM: Curcumin potentiates rhabdomyosarcoma radiosensitivity by suppressing NF-kB activity. PLoS One 8: e51309, 2013.

34. Wan XA, Sun GP, Wang H, Xu SP, Wang ZG and Liu SH Synergistic effect of paeonol and cisplatin on oesophageal cancer cell lines. Dig Liver Dis 40: 531-539, 2008.

35. Xu SP, Sun GP, Shen YX, Wei W, Peng WR and Wang $\mathrm{H}$ Antiproliferation and apoptosis induction of Paeonol in HepG2 cells. World J Gastroenterol 13: 250-256, 2007.

36. Sun GP, Wang H, Xu SP, Shen YX, Wu Q, Chen ZD and Wei W: Antitumor effects of paeonol in a HepA-hepatoma bearing mouse model via induction of tumor cell apoptosis and stimulation of IL-2 and TNF-alpha production. Eur J Pharmacol 584: 246-252, 2008.

37. Sun GP, Wan X, Xu SP, Wang H, Liu SH and Wang ZG: Antiproliferation and apoptosis induction of paeonol in human esophageal cancer cell lines. Dis Esophagus 21: 723-729, 2008.

38. Li N, Fan LL, Sun GP, Wan XA, Wang ZG, Wu Q and Wang H: Paeonol inhibits tumor growth in gastric cancer in vitro and in vivo. World J Gastroenterol 16: 4483-4490, 2010.

39. Babar IA, Czochor J, Steinmetz A, Weidhaas JB, Glazer PM and Slack FJ: Inhibition of hypoxia-induced miR-155 radiosensitizes hypoxic lung cancer cells. Cancer Biol Ther 12: 908-914, 2011.

40. Bayer C and Vaupel P: Acute versus chronic hypoxia in tumors: Controversial data concerning time frames and biological consequences. Strahlenther Onkol 188: 616-627, 2012.
41. Meijer TW, Kaanders JH, Span PN and Bussink J: Targeting hypoxia, HIF-1, and tumor glucose metabolism to improve radiotherapy efficacy. Clin Cancer Res 18: 5585-5594, 2012.

42. Yoshimura $\mathbf{M}$, Itasaka $S$, Harada $H$ and Hiraoka $M$ Microenvironment and radiation therapy. Biomed Res Int 2013: 685308, 2013

43. Yang X, Yang B, Cai J, Zhang C, Zhang Q, Xu L, Qin Q, Zhu H, Ma J, Tao G, et al: Berberine enhances radiosensitivity of esophageal squamous cancer by targeting HIF-1 $\alpha$ in vitro and in vivo. Cancer Biol Ther 14: 1068-1073, 2013.

44. Belozerov VE and Van Meir EG: Hypoxia inducible factor-1: A novel target for cancer therapy. Anti-Cancer Drugs 16: 901-909, 2005.

45. Teicher BA: Hypoxia and drug resistance. Cancer Metastasis Rev 13: 139-168, 1994.

46. Wang J,Liu Q and Yang Q: Radiosensitization effects of berberine on human breast cancer cells. Int J Mol Med 30: 1166-1172, 2012.

47. Rozman A, Silar M and Kosnik M: Angiogenin and vascular endothelial growth factor expression in lungs of lung cancer patients. Radiol Oncol 46: 354-359, 2012.

48. Semenza GL: Hypoxia-inducible factors: Mediators of cancer progression and targets for cancer therapy. Trends Pharmacol Sci 33: 207-214, 2012

49. Gottschalk AR, Doan A, Nakamura JL, Stokoe D and Haas-Kogan DA: Inhibition of phosphatidylinositol-3-kinase causes increased sensitivity to radiation through a PKB-dependent mechanism. Int J Radiat Oncol Biol Phys 63: 1221-1227, 2005.

50. Kim DW, Huamani J, Fu A and Hallahan DE: Molecular strategies targeting the host component of cancer to enhance tumor response to radiation therapy. Int J Radiat Oncol Biol Phys 64: 38-46, 2006.

51. Lin HK, Yeh S, Kang HY and Chang C: Akt suppresses androgen-induced apoptosis byphosphorylating and inhibiting androgen receptor. Proc Natl Acad Sci USA 98: 7200-7205, 2001.

52. De Luca A, Maiello MR, D'Alessio A, Pergameno $M$ and Normanno N: The RAS/RAF/MEK/ERK and the PI3K/AKT signalling pathways: Role in cancer pathogenesis and implications for therapeutic approaches. Expert Opin Ther Targets 16 (Suppl 2): S17-S27, 2012.

53. Porta C, Paglino C and Mosca A: Targeting PI3K/Akt/mTOR signaling in cancer. Front Oncol 4: 64, 2014.

54. Xue Q, Hopkins B, Perruzzi C, Udayakumar D, Sherris D and Benjamin LE: Palomid 529, a novel small-molecule drug, is a TORC1/TORC2 inhibitor that reduces tumor growth, tumor angiogenesis, and vascular permeability. Cancer Res 68: 9551-9557, 2008.

55. Sparks CA and Guertin DA: Targeting mTOR: Prospects for mTOR complex 2 inhibitors in cancer therapy. Oncogene 29: 3733-3744, 2010

56. Abraham RT: mTOR as a positive regulator of tumor cell responses to hypoxia. Curr Top Microbiol Immunol 279: 299-319, 2004. 